\title{
An overview of PERA and the Purdue Methodology
}

\section{T.J. Williams}

In this short chapter we will present only an overview or eagle's eye view of this Architecture and its meaning and the gist of its various ramifications and uses without describing all of its details. For this purpose we will concentrate our early discussion on a computer integrated manufacturing (CIM) system in a factory making relatively common metal products. This is the easiest application of the Architecture to describe. The later part of this discussion will then show the extension of this Architecture to cover any type of Enterprise endeavor and not just CIM in the factory.

The Architecture is fully described in [1].

\subsection{A STRUCTURE FOR THE PURDUE ENTERPRISE REFERENCE ARCHITECTURE}

Fig. 8.1 presents the skeleton diagram or framework against which all of the work carried out with the Architecture can be discussed. This structure, progressing from top to bottom, represents the life history of the enterprise integration project from its initial concept through the stages of functional analysis, functional design or specification, detailed design, construction and installation to operation and finally to obsolescence. There is only a pseudo time scale involved in this since no exact time dimension is implied. However, most, if not all, projects progress through these various stages.

As will be readily seen in the discussion to follow, the several steps and blocks indicated in the progression through the structure of Fig. 8.1, provide important information regarding the work to be done at each step or block in developing the CIM system. They can also be used to indicate at each step or block the project aids available; applicable modelling or analysis techniques which can be used; example systems in the literature which would be helpful illustrations at that point; and a great deal of other 


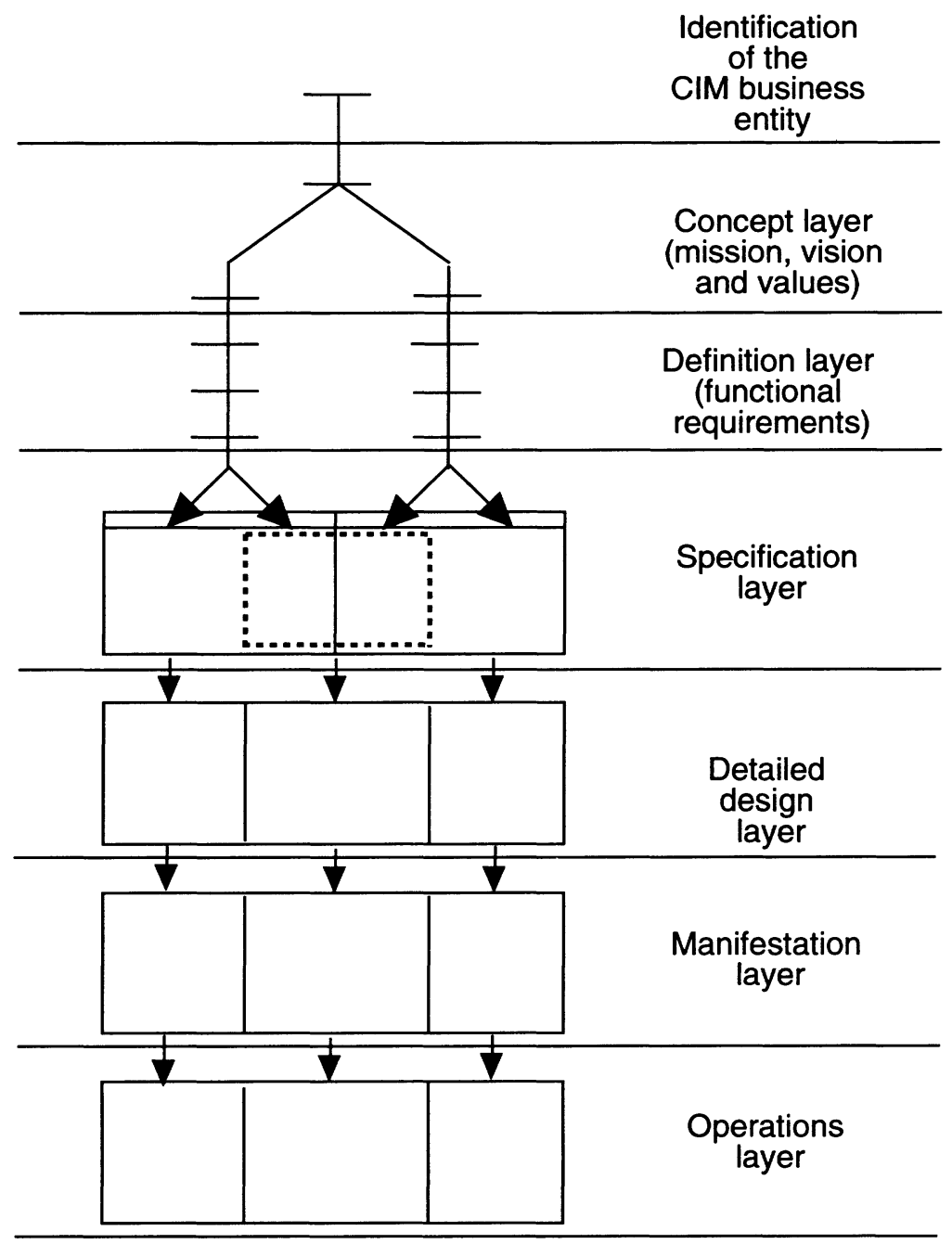

Figure 8.1 A layering of the Purdue Enterprise Reference Architecture in terms of the types of tasks which are occurring within those regions on the graphical representation of the architecture.

important information for the practitioner of enterprise integration. Much of the content of the referenced text [1] involves an explanation of what is done at each step or block in the architecture and how that relates to the work of adjacent steps or blocks. 


\subsection{DESCRIPTION OF THE CONCEPT AND DEFINITION LAYERS OR PHASES}

Note that the structure begins at the top with the identification of the CIM Business Entity, the factory or section of plant in which the contemplated enterprise system is to be installed. We then proceed to develop the Concept Phase or Concept Layer. Any enterprise integration program must be business driven and reflect the goals and aspirations of management concerning the expected outcome of the integration endeavor. Therefore the first requirement is to establish management's mission, vision, and values for the program as expressed in their goals, objectives, mandates, etc., concerning the program. This is shown in Fig. 8.2.

Management's requirements as expressed by the mission, vision and values and related statements are then converted into policies concerning the design, development, construction and operation of the completed factory manufacturing integration unit. The resulting policies, which complete the Concept Phase, are converted into a set of Functional Requirements which define the tasks which our proposed integration program must be able to carry out when completed in order to fulfill the mission, policies, etc., already expressed by management.

These requirements are then voiced in the form of a set of elementary, modular tasks which when implemented will satisfy these requirements. These elementary tasks are then connected together to form a set of functional modules and finally the functional modules themselves are further connected into networks.

Since there are only two basic types of tasks which can be carried out in the manufacturing facility:

1. Those related to the physical manufacturing operations themselves, and

2. Those related to information concerning the manufacturing operations and their control, i.e. sensor readings, control commands, scheduling information, production data, etc.

There are two and only two streams required to define the functional requirements of the proposed system. We shall call these respectively the information (left hand) and manufacturing (right hand) side of the Architecture up to this point.

We have used networks as the method for graphically displaying the functional requirements since these are the popular mode today. On the information side these may become data flow diagrams [2,3], IDEF0 diagrams $[4,5]$ or entity relationship diagrams [6,7]. Many other graphical and computer based schemes have also been proposed. On the manufacturing 


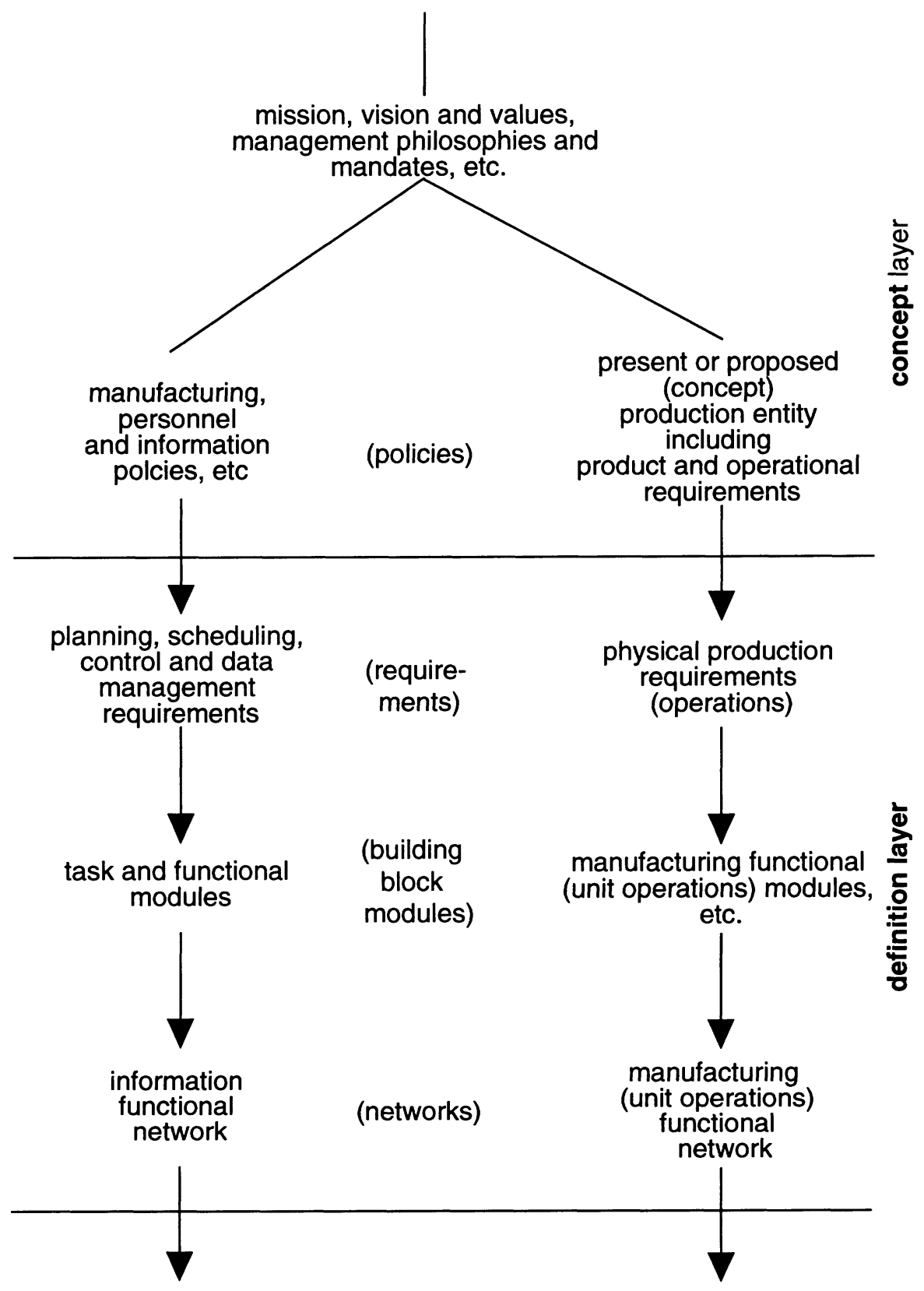

Figure 8.2 Definition of the components of the concept and definition layers. 
side these networks are commonly expressed as process flow diagrams, and material and energy flow diagrams. The development of the modelling of the tasks and functional modules and their collection into macromodules and networks on both sides of the Architecture are thoroughly covered in Chapter 3 of the referenced text [1]. The resulting networks, if sufficiently detailed, will satisfy the functional requirements definition for the CIM system for both types of tasks and functions required and therefore for both sides of the Architecture.

Once the functional requirements are satisfied we are ready to consider how we will implement these requirements. Note that up to this point, this has not been a consideration. Provided all functional requirements are met, it makes no difference what method of implementation is used, i.e. it makes no difference whether they are conducted by humans or machines (or in what type of equipment or where). All of the latter considerations are implementation details. Therefore, as carried out here, any discussion of the place of the human can be postponed in the manufacturing system development until after all tasks and functions are defined.

The range of human skills, muscle power, and other measures of human capability as well as the corresponding abilities of mechanical and electronic devices are such that not all of the tasks in any manufacturing facility can be carried out by either humans or machines alone. Thus we must provide for both humans and machines in carrying out both the information requirements and the manufacturing requirements.

Remember that we have defined all tasks in a modular and functional fashion. This modular and functional character remains regardless of how they are implemented at the moment. Thus, if one should wish to convert any part of the system later in the life of the project from human to machine for implementation or vice versa, the work required should involve only the definition of the alternate implementation and the provision of the proper interfaces to connect the new implementation means into the prevailing system to accomplish the transition.

The endeavor now facing us is to convert the two task streams (information and manufacturing) into three implementation streams (comprising respectively, computer and other control system elements, humans, and manufacturing equipment). Since each of these new streams will eventually have a physical manifestation it is important at this point to decide how to name them. 


\subsection{A SYSTEM OF NOMENCLATURE}

In the manufacturing and enterprise modelling disciplines the word architecture has two different, although related, meanings. Many architectures, including most of those referenced in the literature, are, like this one, a structure or reference framework by means of which one can discuss many different aspects of topics concerning the CIM system or enterprise involved. The other use of the word, relating more to its traditional meaning, concerns the physical structure of the system we are considering. How do the parts connect together, etc.? This latter is especially common in discussing the physical organization of computer and communications systems, for example.

The three streams we are now going to consider involve the use of both definitions of the word, architecture, as defined above. With apologies to the reader for any confusion it may cause, we would now like to define not three, but five subarchitectures of the Purdue Enterprise Reference Architecture. The first two of these are shown in Fig. 8.3. They represent merely the one-for-one implementation of the functional tasks already discussed without yet defining the means of implementation. These will be important to our later discussions, hence their definition here.

However, as we have already noted, some of the tasks in both functional streams must be implemented via human activities. Therefore the structure of Fig. 8.3 must be modified as shown in Fig. 8.4. Part of the tasks of the Information Architecture are carried out by computers and other electronic, pneumatic, or mechanical devices (these form the Information Systems Architecture). Others are carried out by humans (these form part of the Human and Organizational Architecture). Note again that it is the functional tasks that are being distributed here. Therefore the functional definition has not been changed. Only their method of implementation has been decided.

Likewise on the manufacturing side, part of the tasks of the Manufacturing Architecture are carried out by physical equipment (these form the Manufacturing Equipment Architecture). Others are carried out by humans (these form the remainder of the Human and Organizational Architecture). Again, as before, these are functional tasks that have been distributed while their functional definitions have not changed. It is very important to make this distribution at this stage since the actual implementations of the resulting three important implementation architectures are so vitally different from each other from here on out in our discussion. 


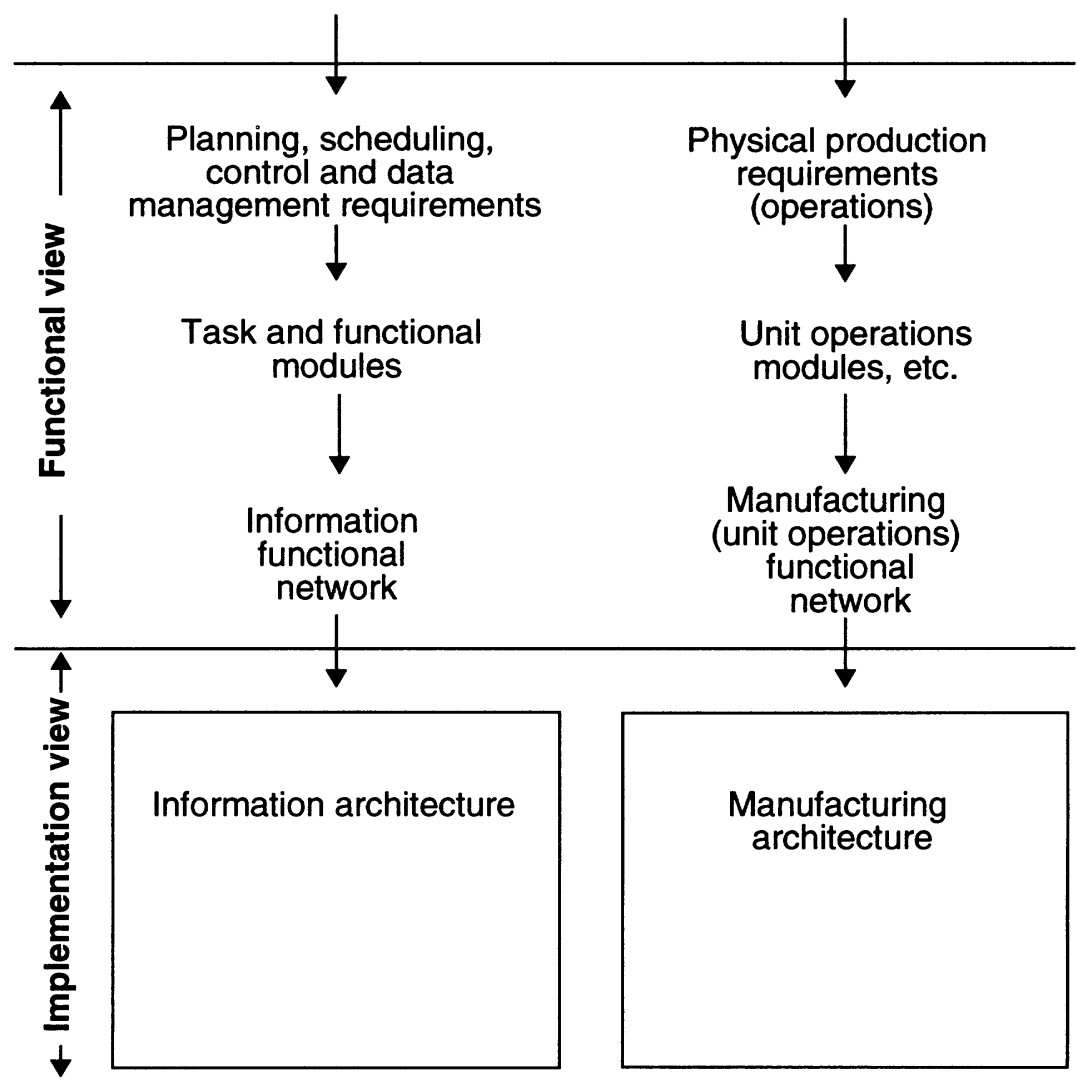

Figure 8.3 Developing the relationships of the several subarchitectures of the Purdue Enterprise Reference Architecture for manufacturing systems.

If no humans were involved, the Information System Architecture would fill the whole width of the Information Architecture block. Likewise the Manufacturing Equipment Architecture would fill the whole width of the Manufacturing Architecture. The result would be the so called 'lights out' plant, i.e. completely automated.

Therefore the dashed lines in Fig. 8.4 separating the Human and Organizational Architecture from the other two implementation architectures represent the degree of automation used in making the decision as to where specific tasks fall between the three architectures. These lines can be defined as shown overleaf. 


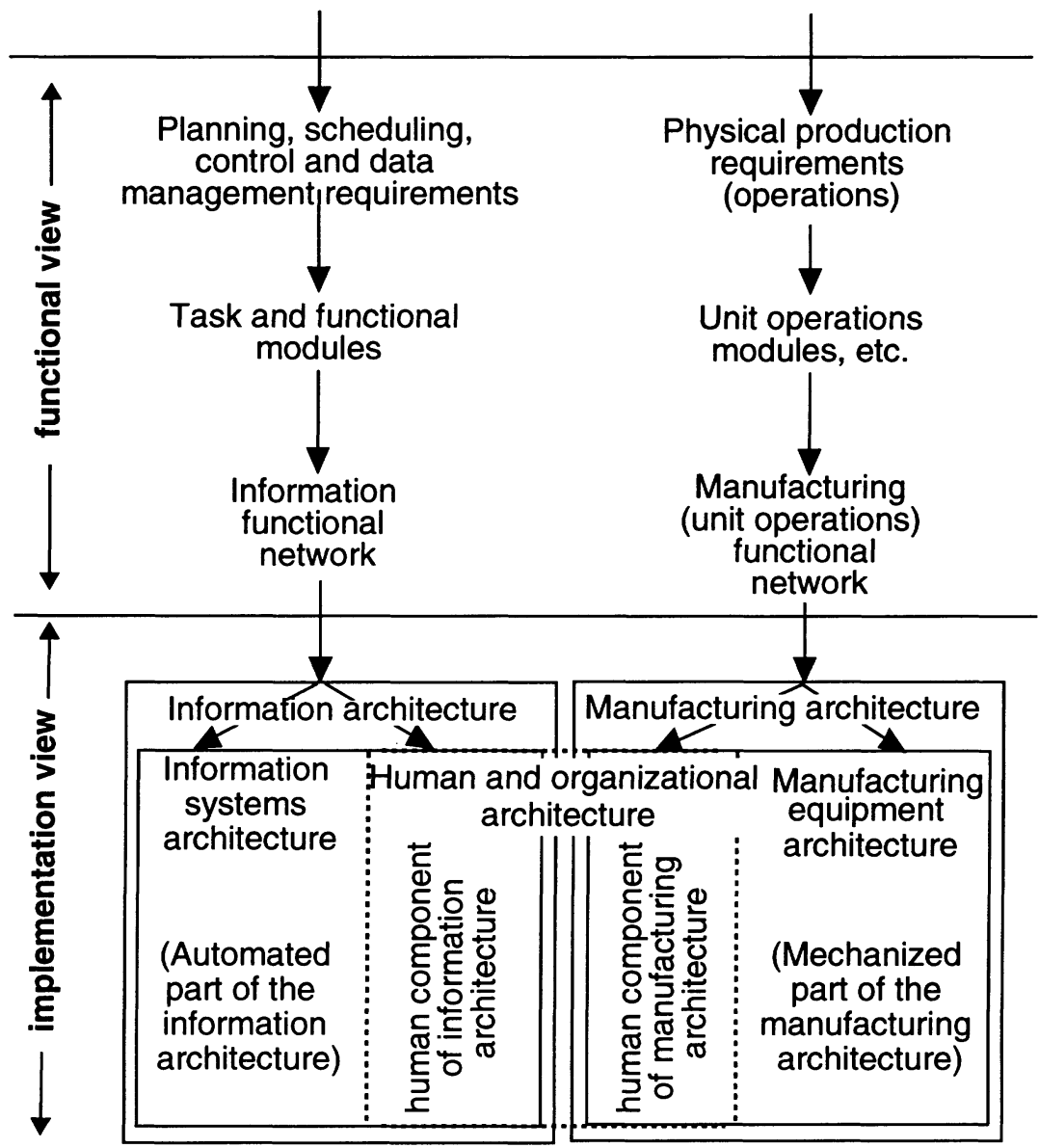

Figure 8.4 Division of the implementation view into the three implementation architectures.

\subsection{DEFINITION OF THE PLACE OF THE HUMAN AND ORGANI- ZATIONAL ARCHITECTURE}

There is a line which can be called the Automatability line which shows the absolute extent of technology in its capability of actually automating the tasks and functions of the manufacturing system of the CIM Business Entity. It is limited by the fact that many tasks and functions require human innovation, and cannot be automated with presently available technology (see Fig.8.5). 


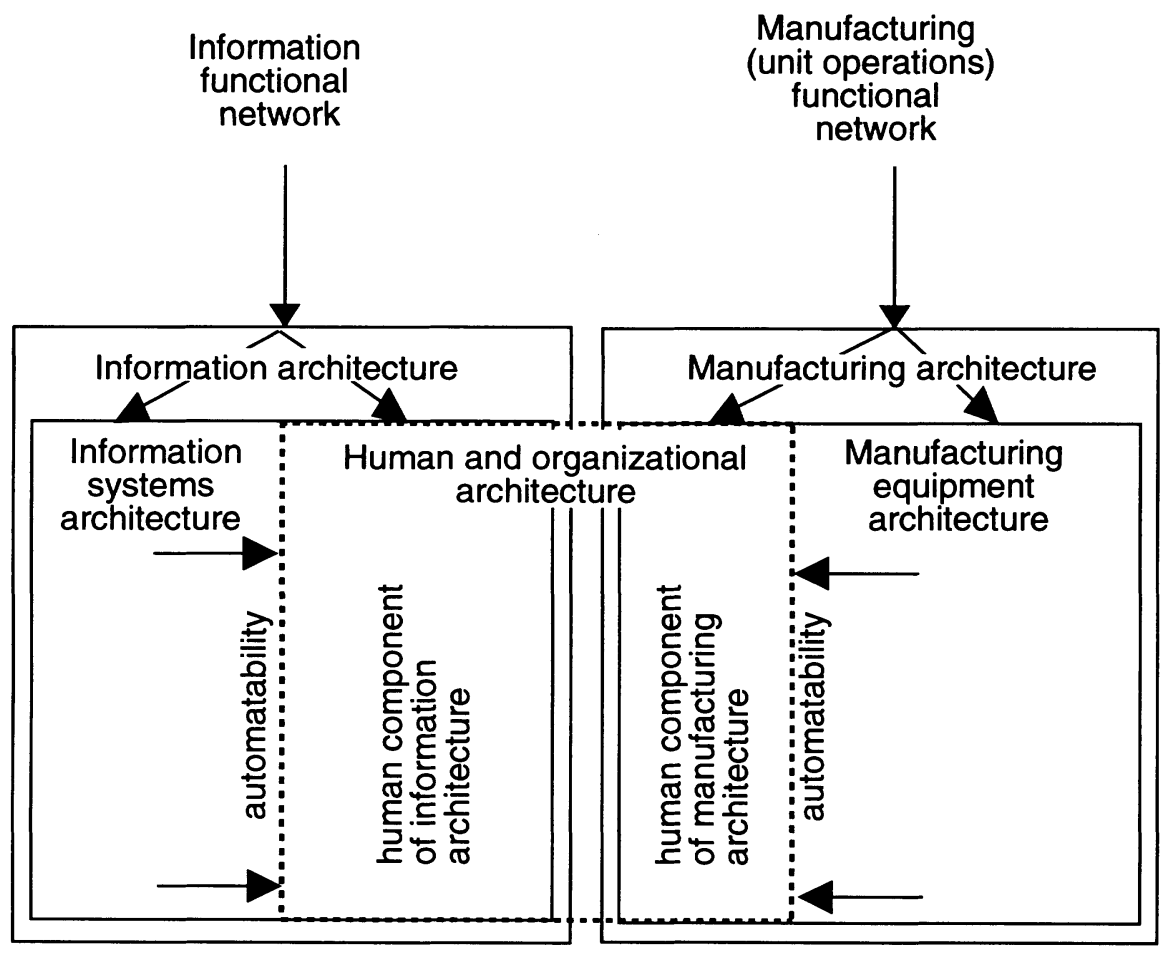

Figure 8.5 Definition of the human and organizational architecture showing the automatability line.

There is another line, which can be called the Humanizability line, which shows the extent to which humans can be used to actually implement the tasks and functions of the integration system of the CIM Business Entity. It is limited by human abilities in speed of response, breadth of comprehension, range of vision, physical strength, etc. Of course, prior to the industrial revolution most information functions in manufacturing were human implemented (see Fig. 8.6).

There is still a third line which can be called the Extent of Automation line (Fig. 8.7) which actually defines the boundary between the Human and Organizational Architecture and the Information Systems Architecture on the one hand, and between the Human and Organizational Architecture and the Manufacturing Equipment Architecture on the other. The Extent of Automation line shows the Actual Degree of automation carried out or planned in the integration system of the CIM Business Entity. 


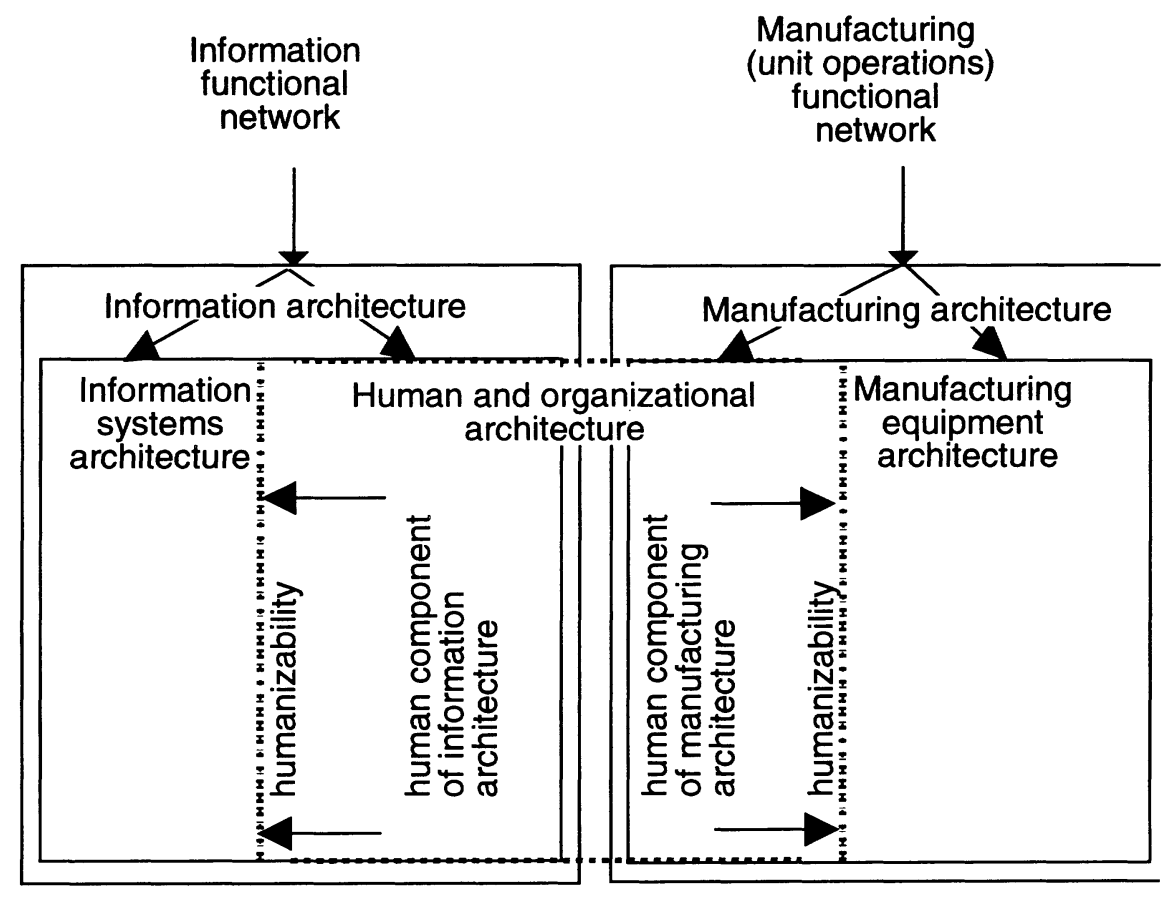

Figure 8.6 Definition of the human and organizational architecture showing the humanizability line.

The location of the Extent of Automation line has:

1. Economic

2. Social (Customs, Laws and Directives, Union Rules), as well as

3. Technological factors in its determination. This is the line actually implemented.

An Automatability line showing the limits of Technology in achieving automation will always be outside of the Extent of Automation line with respect to the automation actually installed. That is, not all of the technological capability for automation is ever utilized in any installation for various reasons. Thus the Human and Organizational Architecture is larger (i.e. more tasks or functions) and the Information System and Manufacturing Equipment Architectures are smaller (fewer functions) than technological capability alone would allow or require.

The Human and Organizational Architecture is implemented mainly through the answering of human relations concerns; such as the level of skills required, the training involved in establishing and maintaining the 


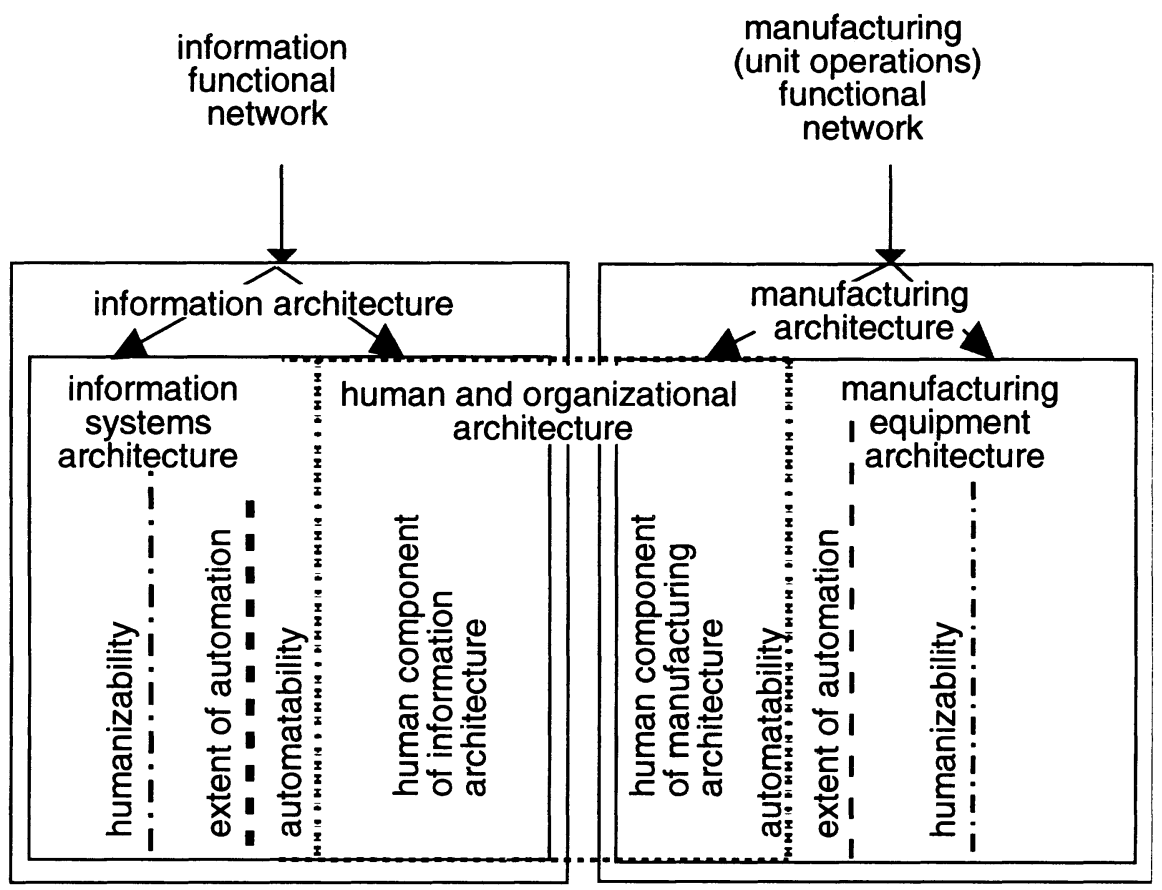

Figure 8.7 Reations of the automatability, humanizability and extent of automation lines in defining the human and organizational architecture.

appropriate skill levels; union concerns such as assignment of personnel to tasks, crafts involved, etc.; such things as the organization used and the resulting reporting paths, pay and vacation, and so forth.

The Information Systems Architecture will involve computer and communications systems choices, database techniques, programming languages, as well as the choice of application programs to satisfy the tasks. The Manufacturing Equipment Architecture will involve the design or procurement of the necessary machines and other manufacturing devices, their appropriate layout in the plant, and the provision for movement of raw materials and semifinished and finished parts about the plant.

Thus again, if the functional requirements are satisfied and if the appropriate coordination is maintained, the implementation of these three architectures can proceed relatively independently of each other. This is a major benefit of this viewpoint particularly when their individual needs are so different. 

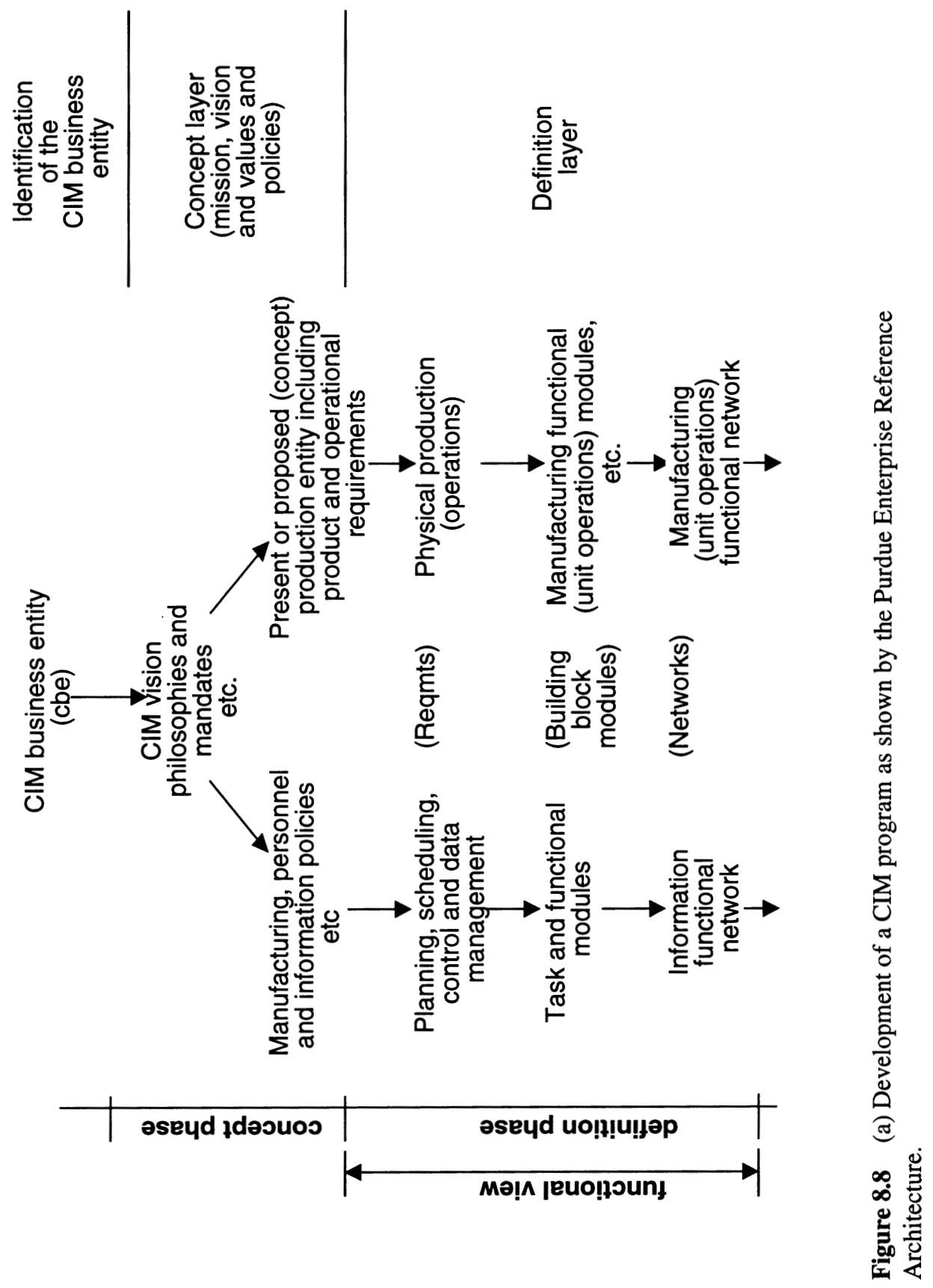


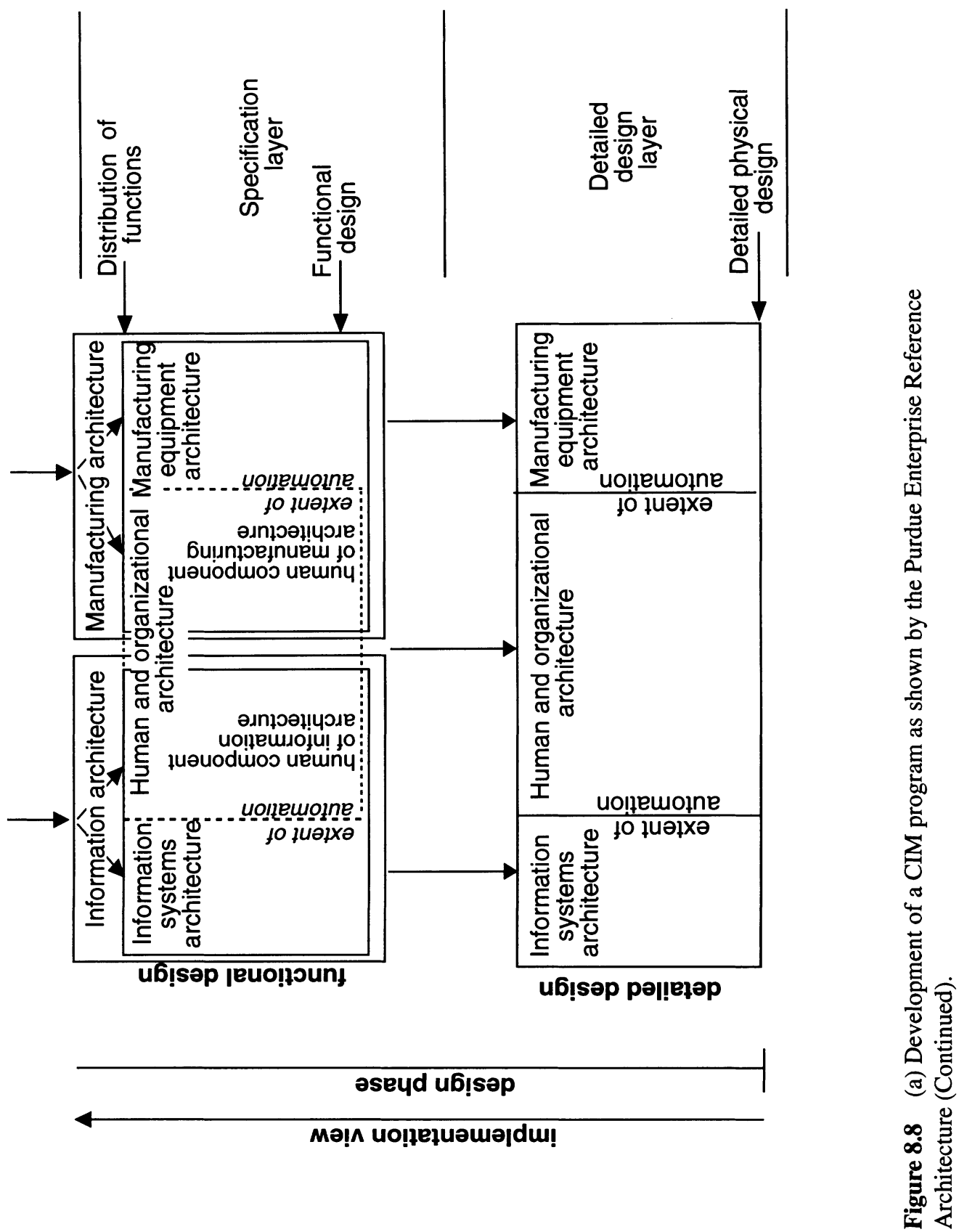




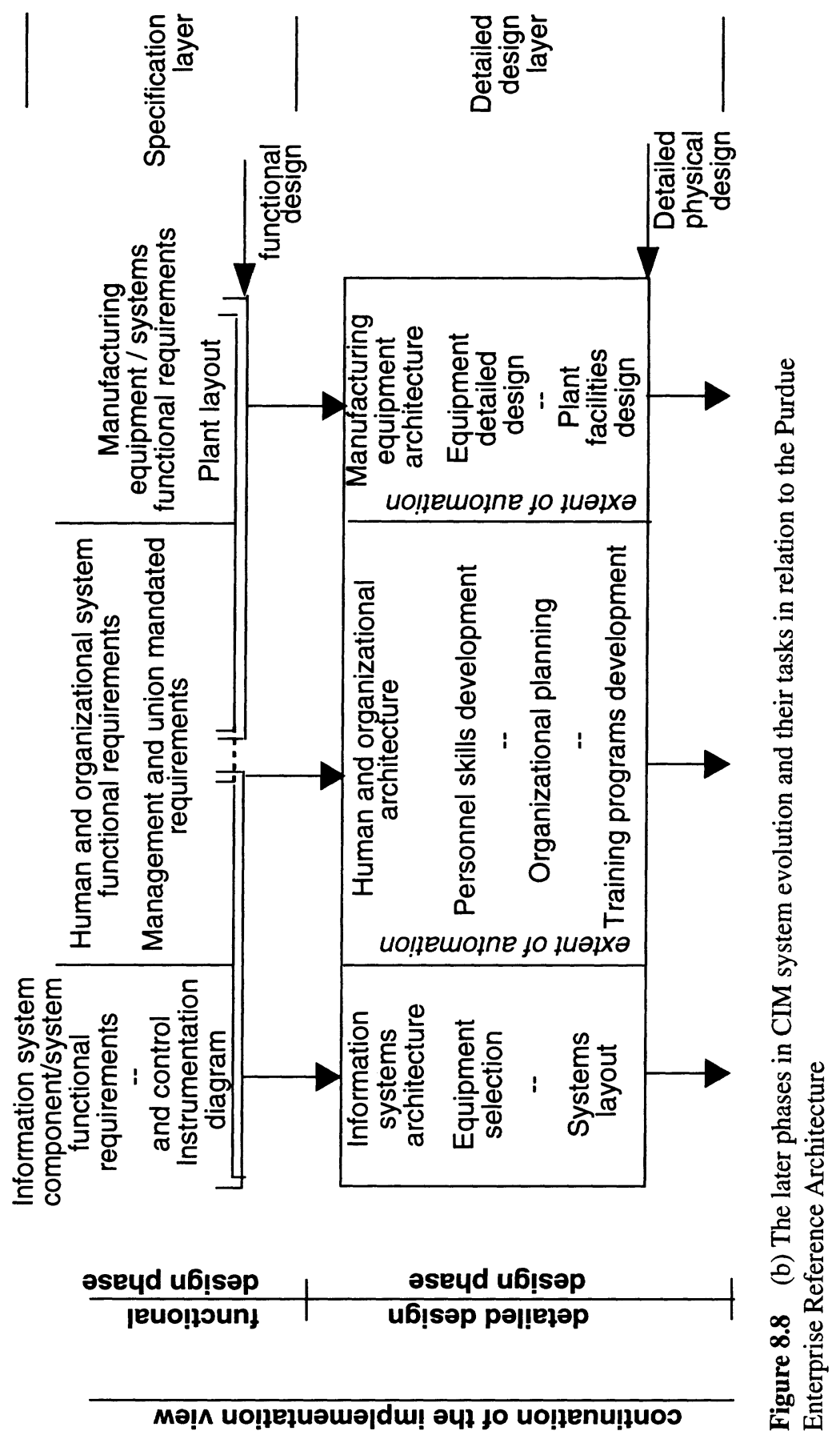




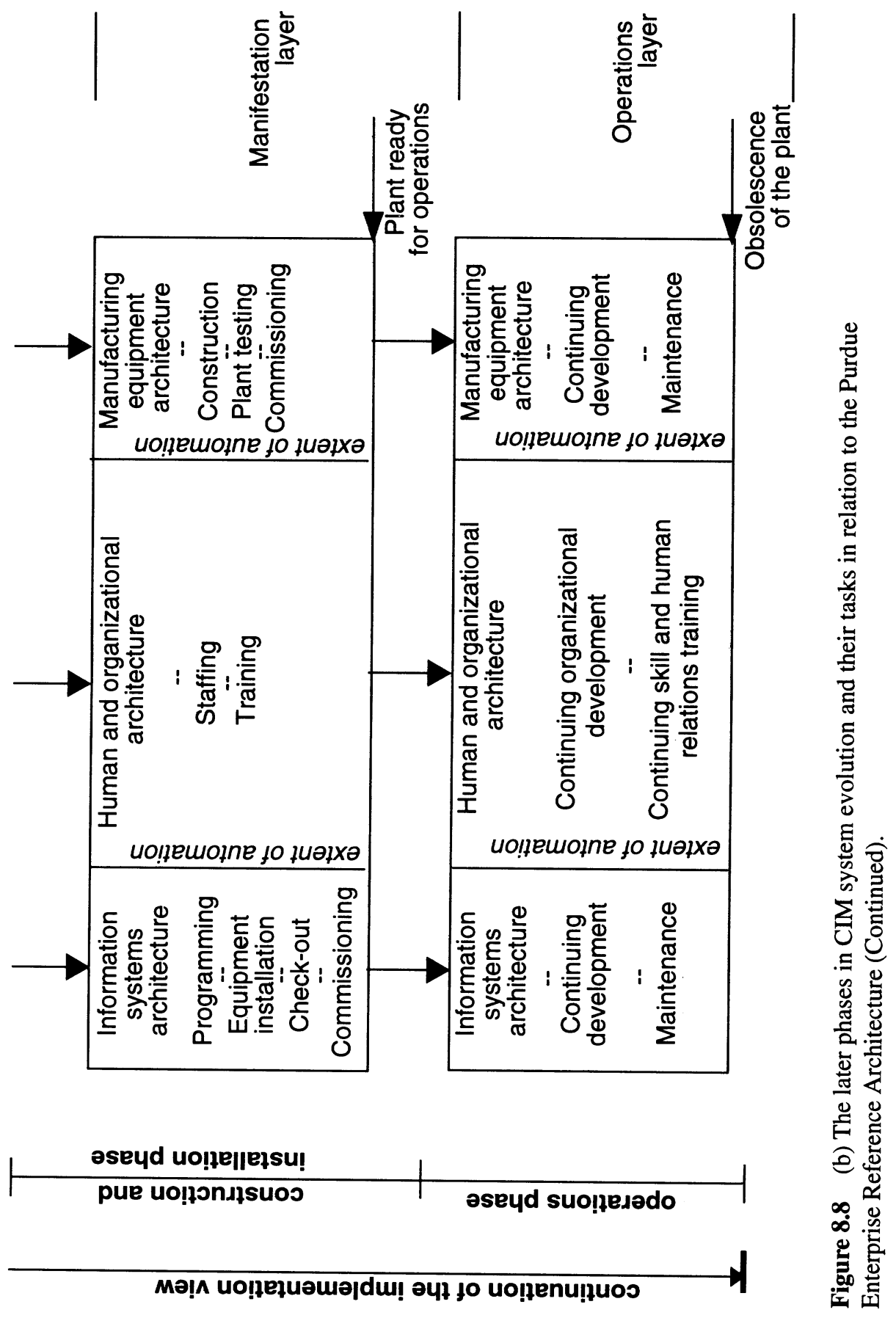




\subsection{DEVELOPMENT OF THE IMPLEMENTATION OF THE CIM SYSTEM}

As shown in Fig. 8.1, implementation of the manufacturing integration program as outlined by the Architecture proceeds from Functional Design or Specification through Detailed Design to Construction, Installation and Check-out and finally to full Operation which continues to Plant Obsolescence.

Figures $8.8 \mathrm{a}$ and $8.8 \mathrm{~b}$ show the fully annotated structure of the architecture, indicating at each layer the types of operations which are carried out concerning each task involved.

\subsection{SUMMARY OF THE OVERVIEW AS RELATED TO MANUFAC- TURING}

As mentioned at the start of this discussion, the straightforward manufacturing implementation as discussed here is the easiest class of applications of the Architecture to describe and was therefore used here to acquaint the reader in general with the description of the use of the Architecture. The explanation of much more complex examples will be brought up next in this discussion.

\subsection{ENTERPRISES AND THE ARCHITECTURE}

Enterprises are organizational entities built to produce goods and/or services in response to customer needs [8]. Enterprises are highly dependent on market trends and needs and customer satisfaction. Enterprises must face two dynamic environments:

1. The external environment characterized by rapidly changing market needs and competition from other vendors serving the same field of endeavor.

2. The internal environment characterized by global objectives, management attitudes, and technological changes.

The Purdue Enterprise Reference Architecture therefore views the enterprise from two distinct viewpoints, that of the business environment as seen by the business user and that of the enterprise's resources (technology of the field of endeavor and information technology). These two descriptions are reflected in the functional requirements modelling layer (Definition Layer), 
in the functional specification modelling layer (Specification Layer) and in the detailed design modelling layer (Detailed Design Layer). The latter two are implementation layers. See Figures 8.1 and 8.8a and 8.8b.

Enterprises may also be defined as entities which exist to carry out a mission or missions. The mission involves one or more tasks carried out with the aid of resources to satisfy one or more desired ends (goals or objectives) in the face of difficulties and limitations (constraints). Note that all of the above applies to every enterprise regardless of size, physical content, or mission carried out. Therefore it should be possible to develop a way of expressing these generic concepts for all enterprises in one form. This is the goal of an Enterprise Reference Architecture.

The architecture of an enterprise can be defined as a structural set of 'models' which represent invariant building blocks of the whole enterprise. The architecture can be considered as a basis for the design and implementation of the whole system of the enterprise. These models, which contain the invariant elements of the system and the relations between these elements, describe respectively the WHAT (what the enterprise system is conceptually composed of) and the HOW (how such a system technically works) and show how to transform the models into realities, i.e. the working system [9]. Thus the architecture is a structure or framework showing the interrelationship of a large number of 'different and separate' models describing parts of the system or their functions (i.e. all or part of the enterprise being considered).

A reference architecture is also a collection of the overall generic functions, descriptions, or behaviors of many (hopefully all) types of systems. This collection can be used for the overall description of these systems, and for the discussion of the overall characteristics, actions or needs of each such system. This document was called an Architecture to distinguish it from the already published Purdue CIM Reference Model [10]. Either term would apply to either document with the interpretation now given the word, architecture, in the CIM literature.

\subsection{EXPANSION OF PERA TO COVER ANY TYPE OF ENTERPRISE (OTHER THAN MANUFACTURING OR PRODUCTION)}

The preceding discussion leads to a set of principles concerning the expansion of this Architecture to include all types of enterprises in its capability to model the development of a program, project or system. 
- All functions and operations on the right hand (Manufacturing) side of the Purdue Reference Architectural Diagram can be represented as relating only to Level 0 of the Purdue Scheduling and Control Hierarchy view of the CIM Reference Model [10]. (See Fig. 8.9, which illustrates the Purdue hierarchy diagram.)

- Conversely all functions and operations shown on the left hand (information) side of the Purdue reference architectural diagram relate only to Level 1 and higher of the Purdue Scheduling and Control Hierarchy view (CIM Reference Model [10]).

- All functions and operations on the right hand (Manufacturing) side can also be shown to relate only to services for the customer, i.e. operation and maintenance of the manufacturing facility to produce products for sale to customers.

- Again conversely all functions and operations on the left hand side (Informational) relate only to the wellbeing of the Business Entity itself, i.e. to its operational control in order to achieve the optimal operating conditions at hand.

The reader will undoubtedly have the most trouble in accepting the implications of Concept 4 above - that the left hand or information side is devoted solely to the wellbeing of the information and control system of the factory containing the integrated system. This is due to two reasons:

- In many cases the products of the factory include a considerable amount of data or information concerning the product and its composition, quality, etc., and often about the company as well.

- The latest 'buzz words' of the TQM (Total Quality Management) process state that, 'everybody works for the customer,' thus apparently violating Concept 4 or vice versa.

These can both be explained. Up to now we have been using the manufacturing system producing a simple product as a discussion example. Frankly, this was done to avoid Problem 2 above as long as possible in order to establish the architecture's principles in the mind of the reader before such questions appeared.

The easiest explanation is to say that, 'The whole company works for the customer.' Thus if the company operates to achieve the highest quality (a control and hence information function) and if the company operates to achieve minimum cost operation or maximum throughput as desired, (both control and hence information functions) then the company has achieved its maximum 'wellbeing' as noted. But the customer has also benefitted from the higher quality, lower cost product, or shorter delivery time possible. Thus these two concepts (TQM and the wellbeing of the enterprise) are not 


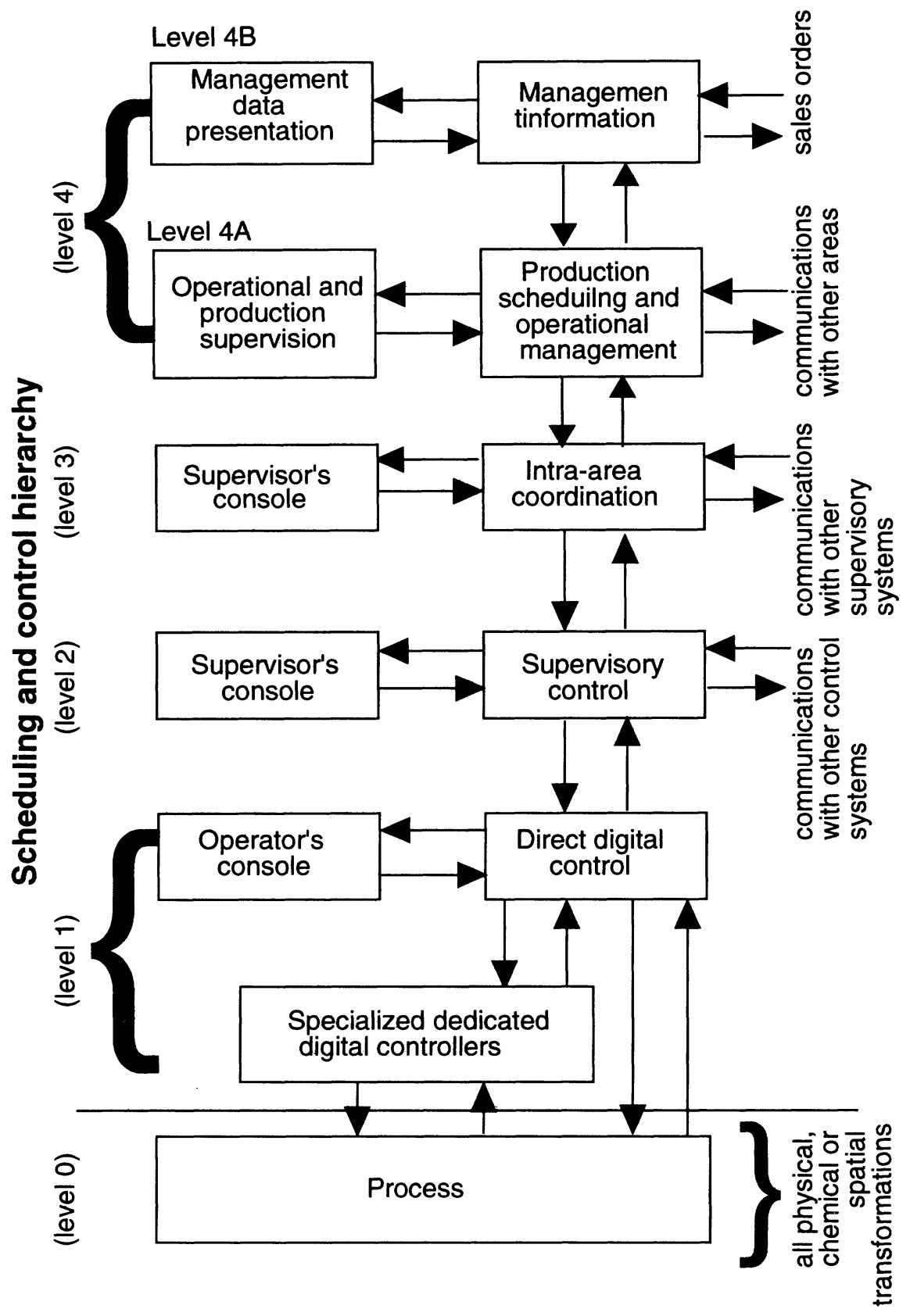

Figure 8.9 Assumed hierarchical computer control structure for an industrial plant (continuous process such as petrochemicals). 
contradictory but complimentary. By being devoted to the wellbeing of the enterprise, the information system achieves the best service to the customers if the requirements are properly stated so that both goals are equally supportive.

The sale of information as a product is the major additional thrust of our discussion of the expansion of the applicability of the Architecture to cover any type of enterprise as will be seen from the material to follow.

Therefore those enterprises whose missions are strictly of an information services nature can also be treated in exactly the same manner as the manufacturing type enterprises just discussed.

As noted earlier, the right hand side of the Business Entity diagram relates to customer services while the left hand side relates to informational services to the enterprise itself. Thus the diagram can be expanded in its coverage to treat all enterprises - not just manufacturing or a information implementation program. Likewise the relationship to the Purdue Reference Hierarchy (Level 0 vs Levels 1-5) also holds true for the general enterprise. The next figures show this. (Figures 8.10 and 8.11).

The Enterprise is a collection of Business Entities (one or more), each of which performs a distinct service to its customers or those of the enterprise. It is often important to split up such an enterprise into separate Business Entities each carrying out its own individual distinct services by the methods being discussed here. Fig. 8.12 shows such a separation of a mission into its distinctly different component parts for a possible example of a manufacturing company. Note that the subunits considered need not be complete selfgoverned entities to qualify. They can be subdivisions of any size or governance. The criteria for separation here is whether or not their mission is sufficiently different from that of the parent organization or their fellows that such a separation in modelling would greatly simplify the modelling task. It is to be considered mainly as a technique for easing the task of a planning or design team in studying the enterprise's structure in relation to the capabilities of the Purdue Enterprise Reference Architecture.

Customer response or the provision of customer services may be carried out in many ways.

- By physical things (i.e. manufactured products; (the type of Business Entity discussed in all the earlier parts of this chapter).

- By pure physical services (transportation of goods or persons, availability of goods or service for purchase, rental (lease), etc., or

- Through the supply of information services (data), (information) to be used by others. 


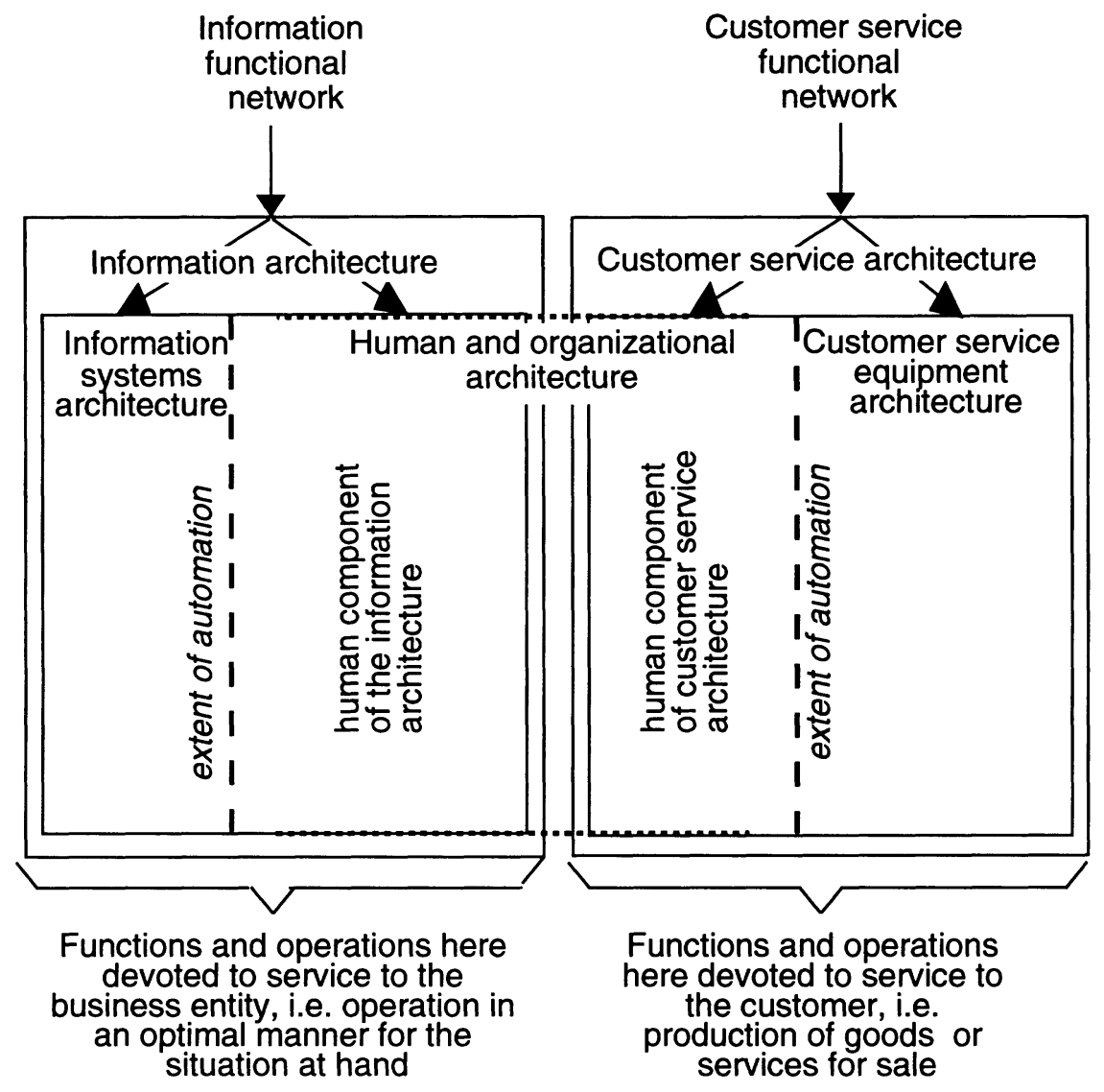

Figure 8.10 Further explanation of the definition of the generic enterprise by the Purdue Enterprise Reference Architecture.

Fig. 8.13 uses the information just developed to modify the labelling of the overall enterprise evolution diagram (Figures $8.8 \mathrm{a}$ and $8.8 \mathrm{~b}$ ) to cover the corresponding generic enterprise (i.e. the production of either goods or services or both). Fig. 8.14 shows how the definition of the tasks of the humans in each section of the Human and Organizational Architecture would change in order to be able to carry out the designated mission. For example, an information services company would employ information services type personnel to perform the desired customer service and thus would have these kinds of personnel in both compartments of the Human and Organizational Architecture. The reader should understand that Fig. 8.13 


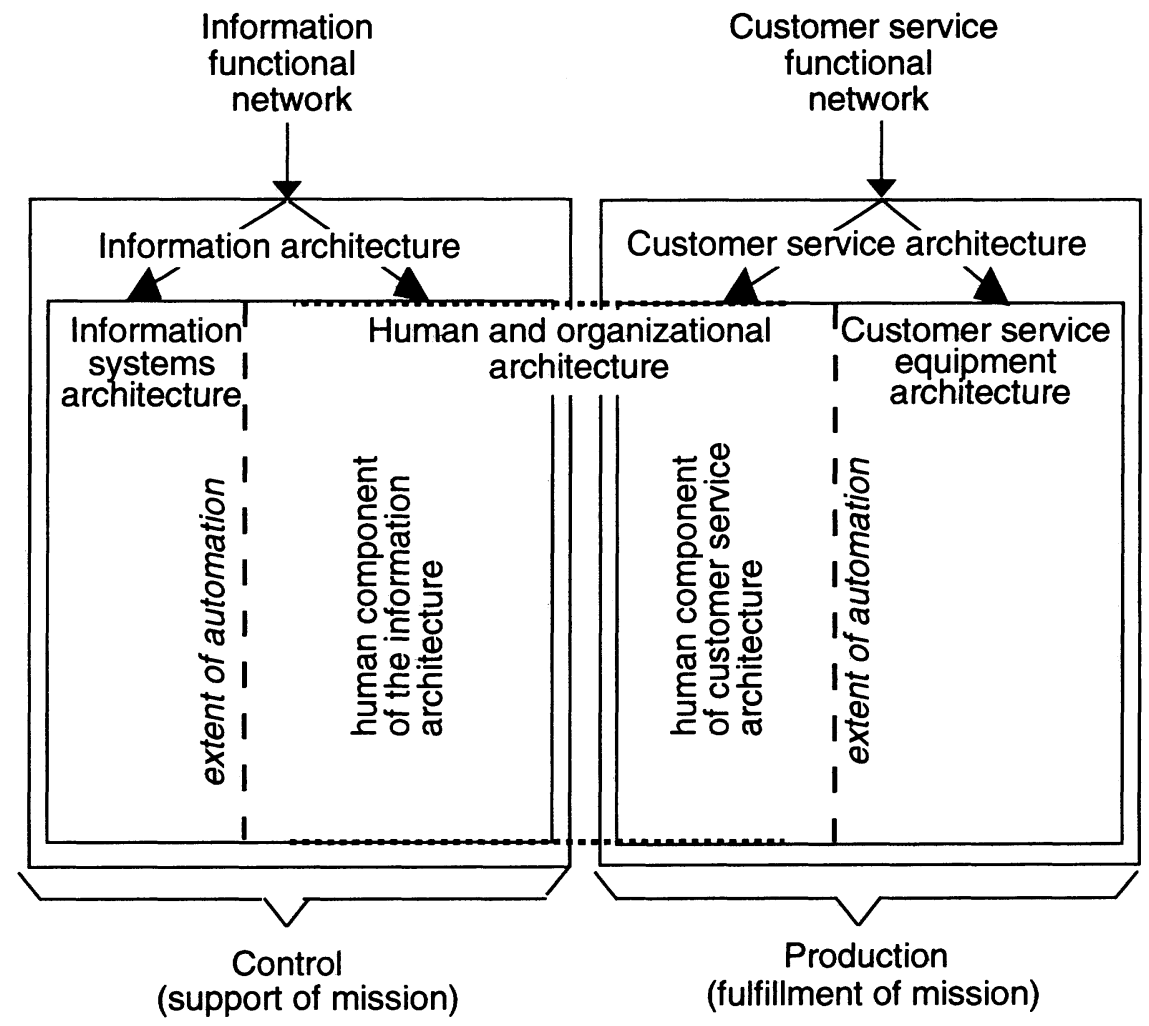

Figure 8.11 Further explanation of the definition of the generic enterprise by the Purdue Enterprise Reference Architecture.

could be extended to cover the total life history of that enterprise as discussed with Fig. 8.8a and $8.8 \mathrm{~b}$ in the case of the manufacturing system. The notations there would bear the same general relationship as used in Figures $8.8 \mathrm{a}$ and $8.8 \mathrm{~b}$. 


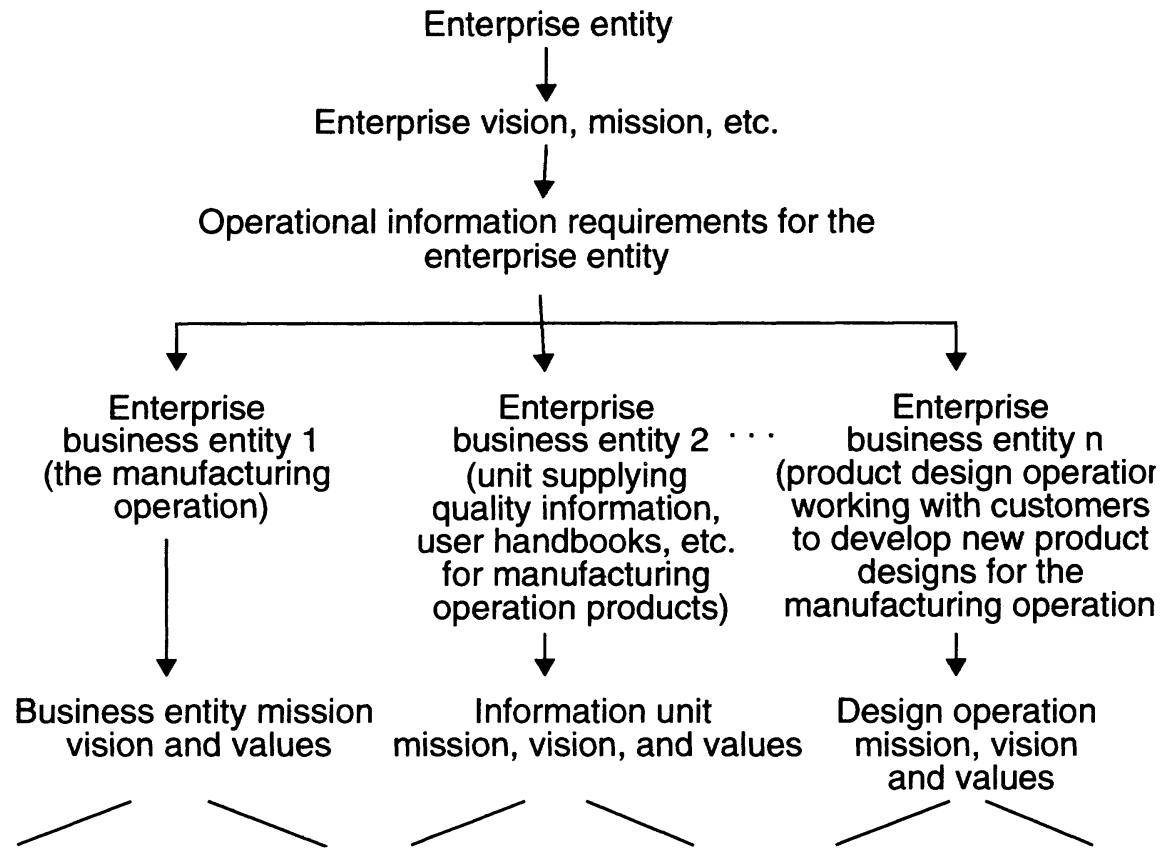

Figure 8.12 Subdivision of the overall enterprise into separate enterprise entities to properly model different enterprise activities (example of possible diversity of subdivision missions).

\subsection{CIM SYSTEM IMPLEMENTATION CONSIDERATIONS AS SHOWN BY PERA AND THE PURDUE METHODOLOGY}

\subsubsection{How the Purdue Methodology works (the master plan is the key)}

The Purdue Enterprise Reference Architecture [1] was originally developed to facilitate the preparation of The Implementation Procedures Manual for Developing Master Plans for Computer Integrated Manufacturing [11] by the Industry-Purdue University Consortium for CIM. The resulting Methodology can be stated as follows:

1. The methodology uses the Purdue Enterprise Reference Architecture [1] as the pattern and the framework for the overall program.

2. It uses the Purdue Reference Model for CIM [10] as the basis for much of the initial data and functional analysis information necessary. 


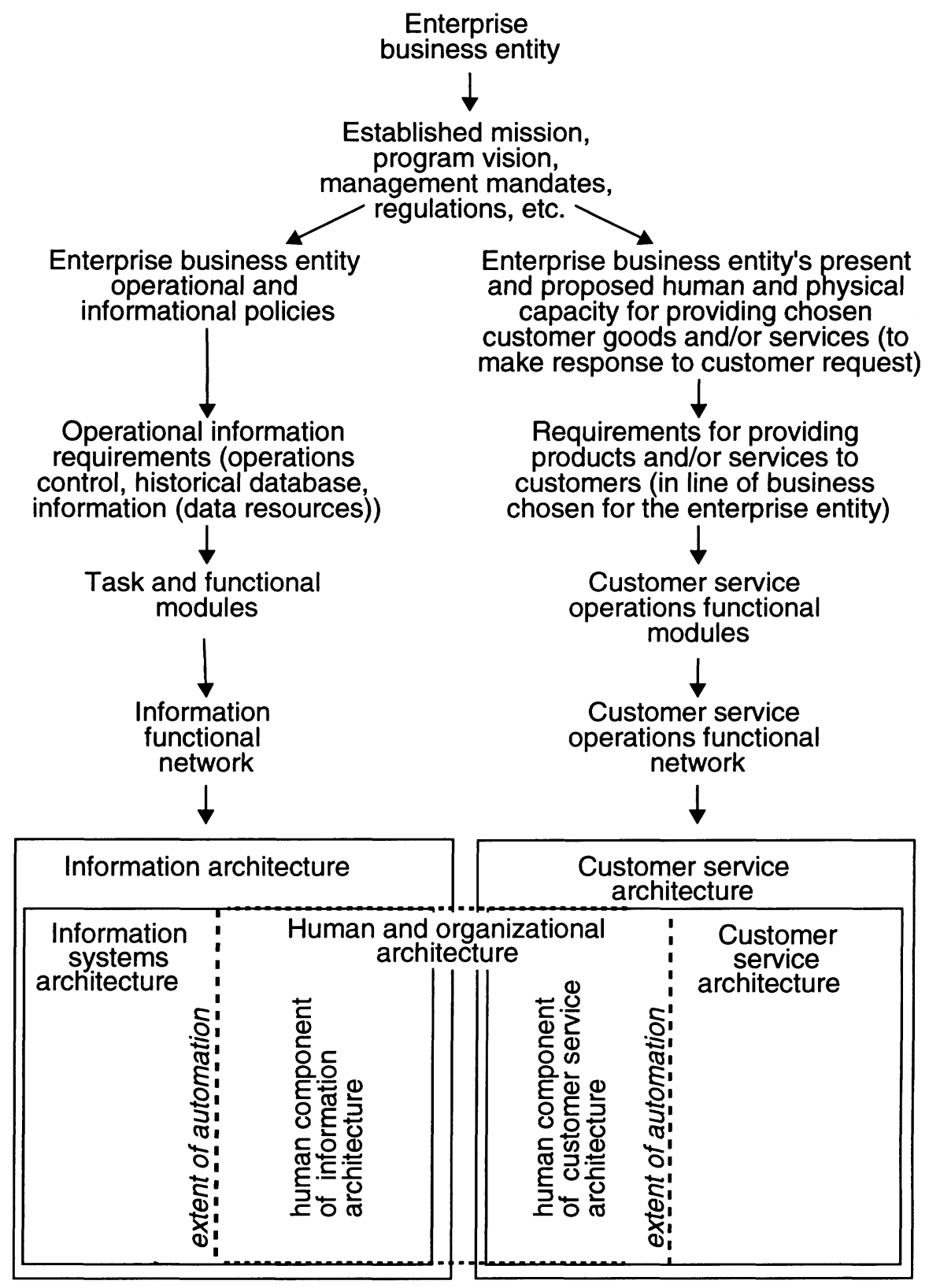

Figure 8.13 The overall diagram for the generic enterprise. 


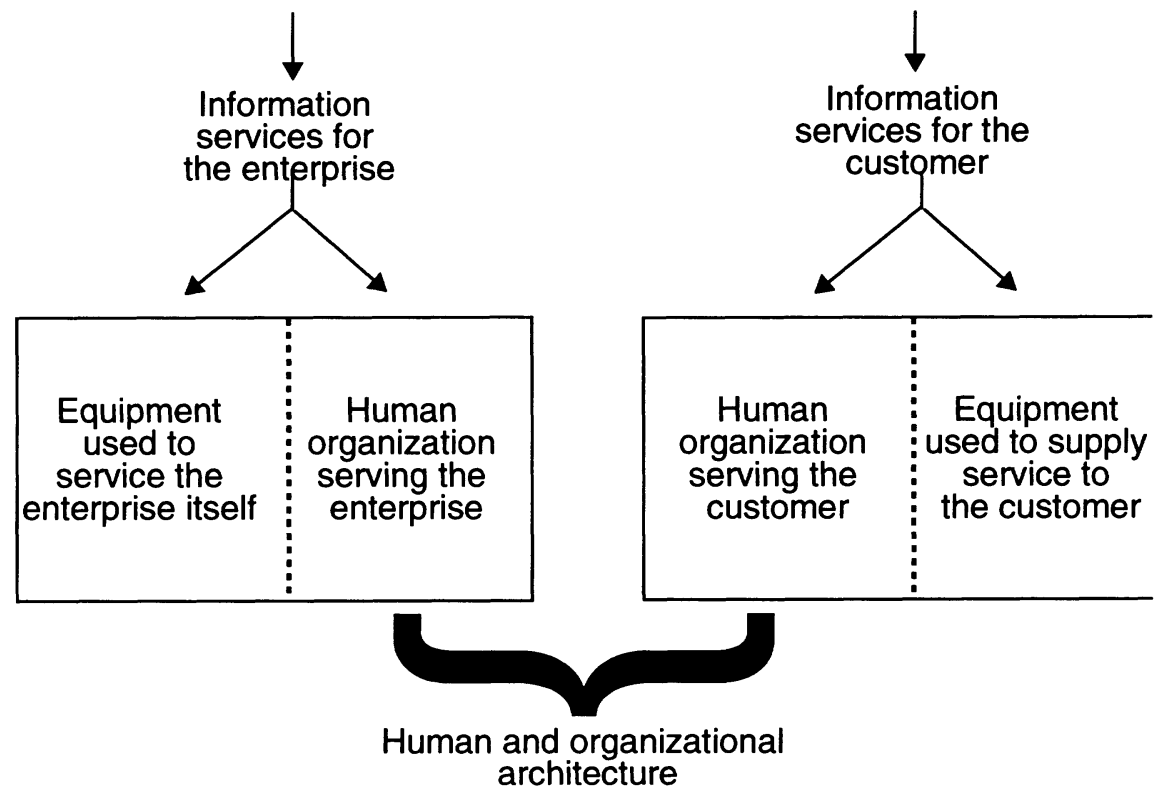

Figure 8.14 Services which are of an innovative information type will be different from the physical service type as shown in this diagram.

3. It uses the Implementation Procedures Manual [11] to help schedule and define the work to be done and to teach the how of master planning.

4. As part of the master planning effort, the methodology develops a CIM Program Proposal which is a set of projects, each within the resource capabilities of the enterprise in terms of manpower and capital, which taken together, fulfill the recommendations of the Master Plan.

5. These projects are then implemented by the Enterprise, as resources permit, following the recommendations of the Master Plan in each case, with the knowledge that on total completion the integration project will also be complete.

What is needed therefore, for each company contemplating a major integration effort, is for the company to develop a Master Plan covering all of the anticipated effort required to integrate the whole of the company or factory operation.

After this, smaller projects within the monetary and personnel resources capability of the company can be initiated with the knowledge that the sum of this and all succeeding projects will result in the final total integration of the company's activities. This will be possible provided that the 
requirements of the initial planning effort or Master Plan be followed in each and every one of the resulting projects.

But the detail and effort required for even the master planning activity is itself large and if done improperly will only lead to difficulties later. Thus there is a need for a methodology to assure that the Master Plan as developed by a company's CIM Planning Team is complete, accurate, properly oriented to future business developments and carried out with the minimum of resources (personnel and capital) necessary.

The Industry-Purdue University Consortium on An Implementation Procedures Manual for Developing Master Plans for Computer Integrated Manufacturing (CIM) has therefore developed such a methodology incorporated in the document of the same title [11]. The Manual presents a detailed description of the tasks involved in developing the Master Plan including its continual renewal. It gives the detail necessary both as to specifics and to the quantity of information and data needed. It specifies the interrelationship of the informational, the human and organizational and the physical manufacturing aspects of the integration considered; the management considerations and concerns; and the economic, cultural and technological factors involved.

\subsection{USING THE IMPLEMENTATION PROCEDURES MANUAL}

\subsubsection{Development of the master plan using the implementation pro- cedures manual}

As noted earlier the Implementation Procedures Manual will provide the user group with all the guidance necessary to help them prepare the company's CIM Program Master Plan. This guidance includes the following information among others:

1. A set of activities that must be performed to develop the appropriate Master Plan for a specific plant site.

2. A detailed description of each activity including: resources required, input information required, methodologies or tools to be used, and the outputs or deliverables from each activity.

3. An approach that clearly ties the Master Plan to business needs.

Fig. 8.15 presents an overview IDEF0 diagram that illustrates how the Manual serves as the mechanism for the preparation of the Master Plan. 


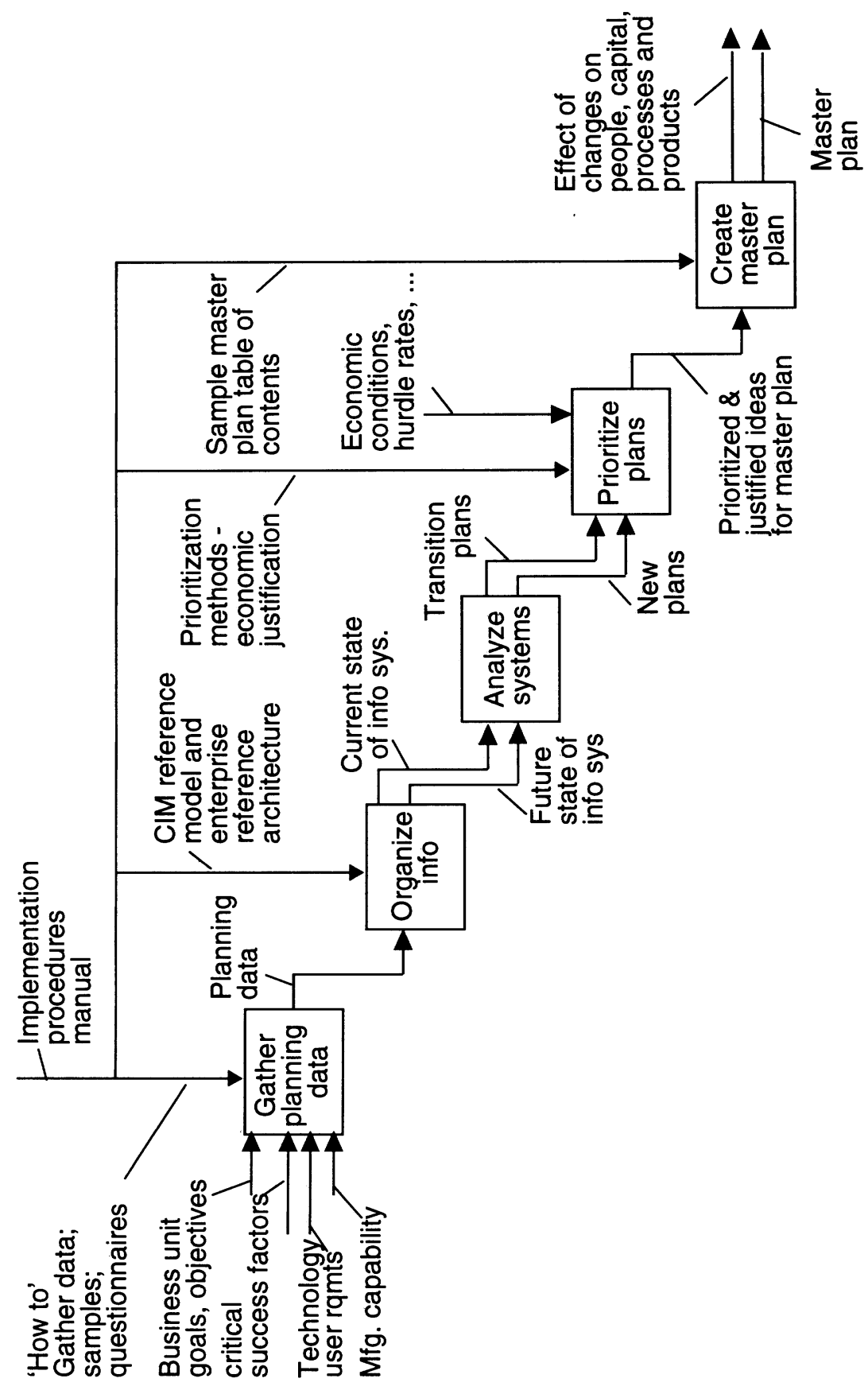

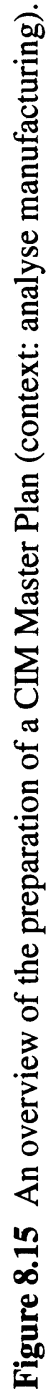




\subsubsection{Key elements in starting a CIM program}

The Consortium Members in preparing this Implementation Procedures Manual believed that several key elements should be in place before any company should undertake an integration project. These key elements should be in place even before attempting the preparation of a Master Plan for an integration program. The first of these includes several very important individuals or groups of individuals.

These are: (1) a Champion, an individual, knowledgeable in CIM technology, who is anxious to promote it, and who serves as a catalyst to push towards such applications; and (2) Sponsorship, or support of upper management and user management personnel who, either separately or as influenced by the Champion, see the potential benefits of integration, and are willing to lend their prestige and influence to investigate and, if viable, promote the CIM program.

During the development of the Manual the Consortium members separated this sponsorship into two elements: (1) the Initiating Sponsor, a high level management individual who lends support and prestige to the work of the Champion and clears the hurdles, and (2) the Steering Committee, a group of stakeholders in the business unit for which the CIM Program is being developed, who lend direct management guidance and support to that effort.

The actual development of the Master Plan itself will be carried out by still another group, the CIM Planning Team. They do the actual analysis and preparation of the plan under the guidance of the Steering Committee.

The other element that must be in place before the CIM Program is officially initiated is the results of a Preliminary Economic Analysis that shows that the Company does have the potential for undertaking one or more potentially successful integration projects.

\subsubsection{An outline of the implementation procedures manual}

In order to carry out the purpose of simplifying the preparation of a Master Plan as much as possible the Manual consists of three main parts. They are: Planning for the Plan or getting ready to develop a Master Plan (Sections I and II); Developing the Master Plan (Section III); and Updating the Master Plan and Continuing Education (Section IV).

In addition there is a group of Appendices that supply additional information to the process of developing the Master Plan. Table 8.1 shows the 
Table 8.1 Implementation procedures manual, showing organization into sections and blocks

\begin{tabular}{ll}
\hline Chapter & Title
\end{tabular}

$\begin{array}{ll}\text { Section I } & \text { Introduction } \\ \text { Chapter I-1 } & \text { Management presentation summary } \\ \text { Chapter I-2 } & \text { Introduction } \\ \text { Chapter I-3 } & \text { Using the implementationprocedures manual }\end{array}$

Section II Preparations for the cim task

Chapter II-1 The task ahead

Chapter II-2 Get management support

Chapter II-3 Build consensus

Chapter II-4 Affirm the enterprise strategies

Chapter II-5 Identify and build the CIM planning team

Section III Prepare the master plan

Block 1 (strategic - affirm strategies)

Chapter III-1 Define the CIM business entity

Chapter III-2 Document the objectives, strategies, business plans,goals and critical success factors to be attained by CIM in the business entity

Chapter III-3 Affirm the to-be manufacturingpolicies

Block 2 (definition - define 'to-be') 
Table 8.1 Implementation procedures manual, showing organization into sections and blocks (Continued)

\begin{tabular}{ll}
\hline Chapter & Title \\
\hline Chapter III-4 & $\begin{array}{l}\text { Identify significant initiatives and opportunities } \\
\text { enabled by cim to achieve goals and objectives }\end{array}$ \\
Chapter III-5 & Define to-be manufacturing functional architecture \\
Chapter III-6 & Define to-be information functional architecture \\
Chapter III-7 & $\begin{array}{l}\text { Define to-be human and organizational functional } \\
\text { architecture }\end{array}$
\end{tabular}

Block 3 (definition - define 'as-is')

Chapter III-8 Document the as-is manufacturing functional architecture

Chapter III-9 Document the as-is information functional architecture

Chapter III-10 Document as-is human and organizational functional architecture

Block 4 (planning - transition planning)

Chapter III-11 Identify required standards selection process

Chapter III-12 Identify logical transition path from as-is to to-be

Chapter III-13 develop training plan

Chapter III-14 Identify feasible solutions in the form of a set of cim projects

Chapter III-15 Analyze costs, benefits and risks for proposed projects

Block 5 (Strategic - finalize master plan) 
Table 8.1 Implementation procedures manual, showing organization into sections and blocks (Continued)

\begin{tabular}{ll}
\hline Chapter & Title \\
\hline Chapter III-16 & Final critical evaluation of the master plan contents \\
Chapter III-17 & Author master plan and deliver for action \\
Section IV & Process of renewal \\
Chapter IV-1 & Master plan renewal process \\
Chapter IV-2 & Plan continuing education and training \\
Appendix I & Modelling methods and tools \\
Appendix II & CIM business entity database \\
Appendix III & $\begin{array}{l}\text { Master plan definitions andexamples } \\
\text { Appendix IV }\end{array}$ \\
Appendix V & $\begin{array}{l}\text { Benchmarking (share and share alike) } \\
\text { Appendix VI }\end{array}$ \\
Appendix VII & $\begin{array}{l}\text { A bibliography of the technical literature relative to } \\
\text { mentation procedures manual }\end{array}$ \\
\hline
\end{tabular}

chapter title list for the Manual indicating their further collection into related subject blocks under the major sections as just noted above.

Fig. 8.16 shows still another method of illustrating the subject matter flow through the Manual and the suggested Master Plan format. Fig. 8.17 outlines the correspondence of the coverage of the Enterprise Reference Architecture and of the CIM Reference Model in relation to the factory, and to the overall enterprise and its business environment. 


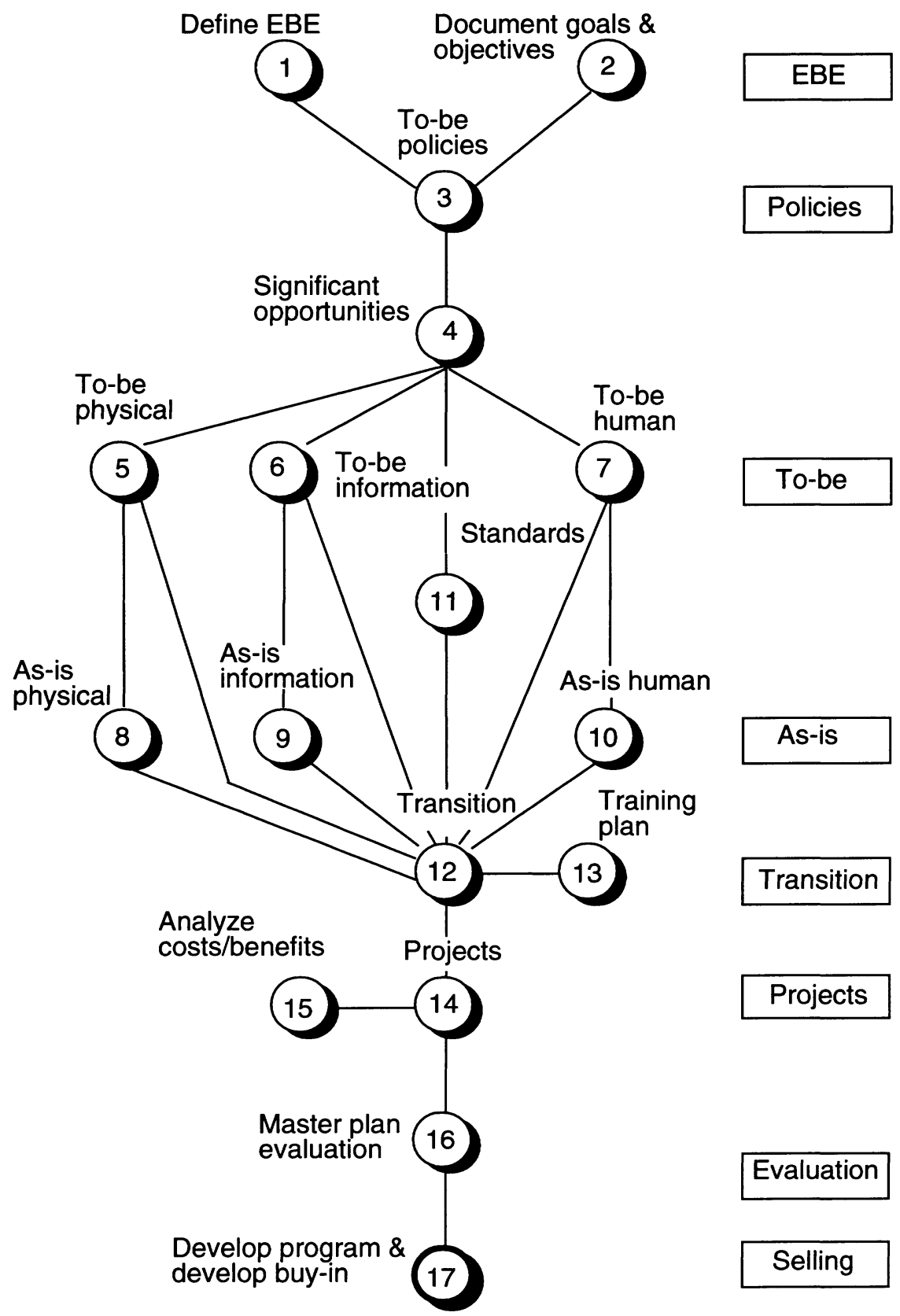

Figure 8.16 Purdue CIM Implementation Procedures Manual flow (numerals refer to manual chapter numbers). 


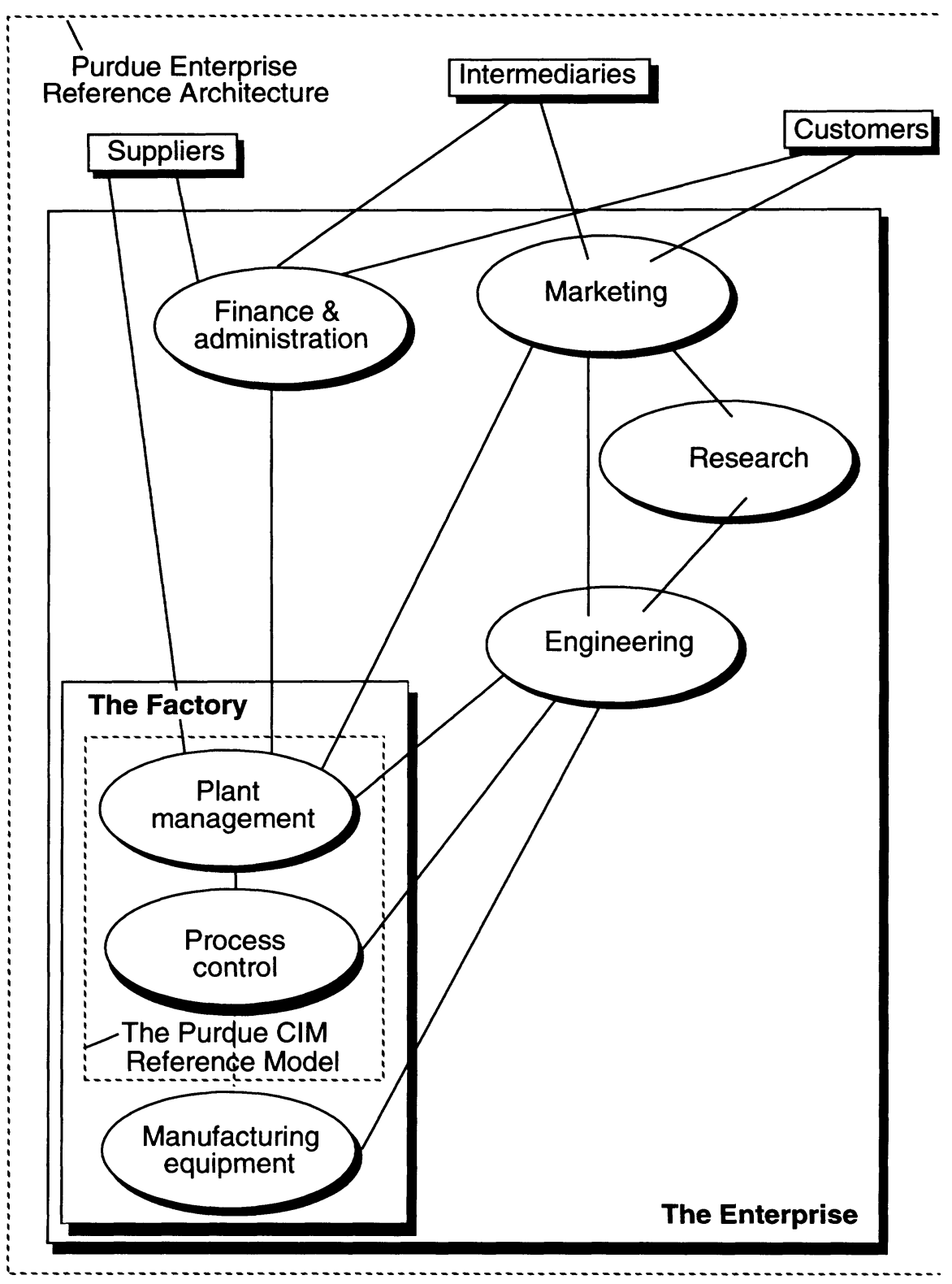

Figure 8.17 Purdue methodology tools in relation to the overall manufacturing enterprise. 


\subsection{REFERENCES}

[4] Anonymous, IDEF0 Function Modeling Manual, ICAM Program Office, Wright-Patterson AFB, OH (1981).

[6] Chen, Peter, 'Principles of Database Design,' In Database Design Based on Entity and Relationship, S. Bing Yao, Editor, Chapter 5, Prentice-Hall Inc., Englewood Cliffs, NJ (1985).

[2] DeMarco, T., Structured Analysis and System Specification, Yourdon Press - Prentice Hall, Englewood Cliffs, NJ (1979).

[9] Doumeingts, G., Vallepir, B., Zanettin, M., and Chen, D., GIM, GRAI Integrated Methodology, A Methodology for Designing CIM Systems, Version 1.0, Special Report, GRAI Laboratory, University Bordeaux I, Bordeaux, France (May 1992).

[8] ESPRIT Consortium AMICE, Open System Architecture, CIMOSA, AD 1.0, Architecture Description, ESPRIT Consortium AMICE, Brussels, Belgium (1991).

[11] Industry-University Consortium, Purdue Laboratory for Applied Industrial Control, An Implementation Procedures Manual for Developing Master Plans for Computer Integrated Manufacturing, Report Number 155, Purdue Laboratory for Applied Industrial Control, Purdue University, West Lafayette, IN (June 1992).

[5] Ross, D. T., 'Applications and Extensions of SADT,' IEEE Computer, Vol 18, No. 4, pp 25-34 (April 1985).

[7] U.S. Air Force (no author) 'Integrated Computer-Aided Manufacturing (ICAM)', Architecture Part II, Vol. V -Information Modeling Manual (IDEF1), AFWAL-TR-81-4023, Wright-Patterson Air Force Base, OH, (June 1981).

[10] Williams, T. J., Editor, A Reference Model for Computer Integrated Manufacturing (CIM), A Description From the Viewpoint of Industrial Automation, Minutes, CIM Reference Model Committee, International Purdue Workshop onIndustrial Computer Systems, Purdue University, West Lafayette, IN (1988), Instrument Society of America, Research Triangle Park, NC (1989).

[1] Williams, T. J., The Purdue Enterprise Reference Architecture, Instrument Society of America, Research Triangle Park, NC (1992).

[13] Yourdon, Edward, and Constantine, L.L., Structured Design: Fundamentals of a Discipline of Computer Program and Systems Design - Edition 2, Prentice-Hall, Englewood Cliffs, NJ (1979) 


\subsection{FURTHER READING}

Anonymous, Data Processing - Open Systems Interconnection - Basic Reference Model, ISO DIS 7498, International Standards Organization, Geneva, Switzerland (December 3, 1980). 